\section{Direct hit by IL-21}

It has been reported that interleukin-21 (IL-21) drives the differentiation of $\mathrm{T}$ follicular helper $\left(\mathrm{T}_{\mathrm{FH}}\right)$ cells and is essential for effective germinal centre B cell responses. However, it was not clear whether the $\mathrm{B}$ cells in the germinal centre are themselves dependent on IL-21 or if the key requirement for IL-21 is in promoting $\mathrm{T}_{\mathrm{FH}}$ cell functions. Two papers published in the Journal of Experimental Medicine now show that IL-21 acts directly on B cells to promote their proliferation and retention in germinal centres.

The studies found that mice lacking IL-21 or its receptor (IL-21R) showed defective IgG1 class switching and antibody affinity maturation following immunization with T celldependent antigens. This defect in antibody generation seemed to result from the early dissolution of germinal centre responses; in the absence of IL-21R signalling, germinal centres formed normally but were not maintained, and the appearance of CD38 ${ }^{+}$ memory B cells was accelerated. Interestingly, and in contrast to previous work, this did not seem to be due to defective generation of $\mathrm{T}_{\mathrm{FH}}$ cells. Instead, using mixed bone marrow chimera experiments with wild-type and IL-21R-deficient donors, the studies identified IL-21R signalling by $B$ cells as the crucial factor for the development of effective germinal centre responses. Furthermore, Zotos et al. showed that a $\mathrm{CD}^{+}$population, presumably $\mathrm{T}$ cells, was an important source of the IL-21 required for the germinal centre B cell response.

Both papers showed that in vivo IL-21R signalling increases B cell expression of B cell lymphoma 6 (BCL-6), a transcription factor that could be regarded as a master regulator of germinal centre formation given its requirement for both $\mathrm{T}_{\mathrm{FH}}$ cell and germinal centre $\mathrm{B}$ cell functions. BCL-6 has well-known anti-apoptotic functions and promotes the follicular retention of lymphocytes; therefore it is possible that BCL- 6 can enhance $T$ cell-dependent $B$ cell responses by increasing the dwelling time of B cells (and subsequent class switching and affinity maturation responses) in the germinal centre.

Yvonne Bordon

ORIGINAL RESEARCH PAPERS Linterman, M. A. et al. IL-21 acts directly on B cells to regulate $\mathrm{Bcl}-6$ expression and germinal center responses. J. Exp. Med. 8 Feb 2010 (doi:10.1084/ jem.20091738) |Zotos, D. et al. IL-21 regulates germinal center B cell differentiation and proliferation through a B cell-intrinsic mechanism. J. Exp. Med. 8 Feb 2010 (doi:10.1084/ jem.20091777)

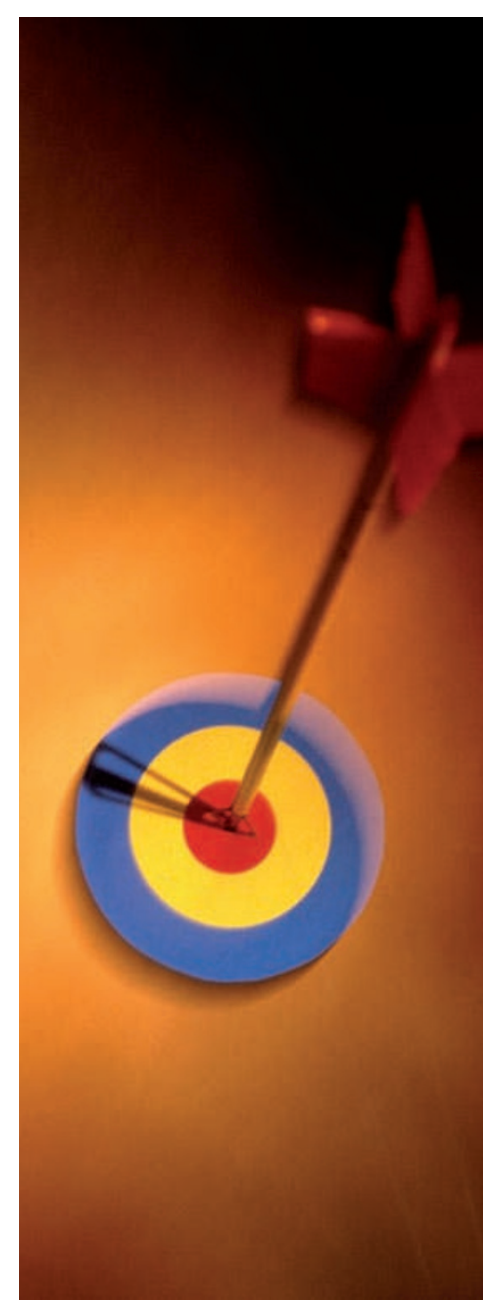

